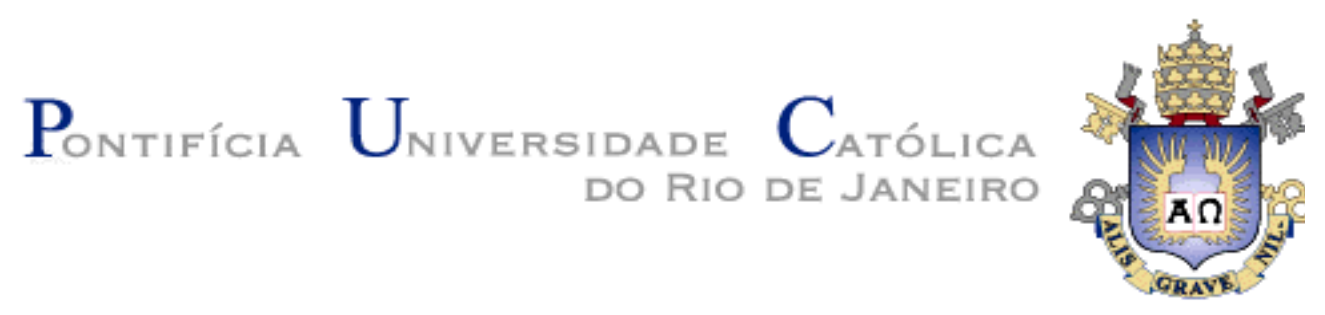

Jenesca Florencio Vicente

\title{
Caracterização Hidrogeológica de uma Área Experimental no Campus da Universidade Federal Rural do Rio de Janeiro
}

\author{
Dissertação de Mestrado
}

Dissertação apresentada como requisito parcial para obtenção do título de Mestre pelo Programa de PósGraduação em Engenharia Civil da PUC-Rio.

Orientadores: Prof. Eurípedes do Amaral Vargas Júnior Prof. José Tavares Araruna Júnior 


\section{Pontifícia Universidade Católica $_{\text {a }}$}

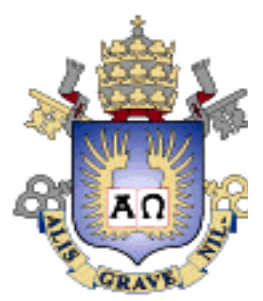

Jenesca Florencio Vicente

\section{Caracterização Hidrogeológica de uma Área Experimental no Campus da Universidade Federal Rural do Rio de \\ Janeiro}

Dissertação apresentada como requisito parcial para obtenção do título de Mestre pelo Programa de PósGraduação em Engenharia Civil da PUC-Rio. Aprovada pela Comissão Examinadora abaixo assinada.

Prof. Eurípedes do Amaral Vargas Júnior Orientador Departamento de Engenharia Civil - PUC-Rio

Prof. José Tavares Araruna Júnior Co-Orientador Departamento de Engenharia Civil - PUC-Rio

Prof. Franklin Antunes Departamento de Engenharia Civil - PUC-Rio

Prof. Euzébio José Gil UFRRJ

Prof. José Eugênio Leal Coordenador Setorial do Centro Técnico Científico - Puc-Rio

Rio de Janeiro, 17 de setembro de 2008 
Todos os direitos reservados. É proibida a reprodução total ou parcial do trabalho sem autorização da universidade, da autora e do orientador.

\section{Jenesca Florencio Vicente}

Graduou-se em Geologia pela Universidade Federal Rural do Rio de Janeiro em 2005. As principais áreas de interesse e linhas de pesquisa são: Hidrogeologia, Geotecnia Ambiental e Geologia de Engenharia.

Ficha Catalográfica

Vicente, Jenesca Florencio
Caracterização hidrogeológica de uma área
experimental no campus da Universidade Federal Rural do
Rio de Janeiro / Jenesca Florencio Vicente ; orientadores:
Eurípedes do Amaral Vargas Júnior, José Tavares Araruna
Júnior. - 2008.
144 f. : il. ; 29,7 cm
Dissertação (Mestrado em Engenharia Civil)-
Pontifícia Universidade Católica do Rio de Janeiro, Rio de
Janeiro, 2008.
Inclui bibliografia
1. Engenharia civil - Teses. 2. Hidrogeologia. 3.
4. Área experimental. I. Vargas Júnior,
Geoquímica.
Eurípedes do Amaral. II. Araruna Júnior, José Tavares. III.
Pontifícia Universidade Católica do Rio de Janeiro.
Departamento de Engenharia Civil. IV. Título.


À minha querida mãe Erinéa, ao meu marido Cristiano José e ao meu filho Antônio José (in memorian). 


\section{Agradecimentos}

Primeiramente a Deus por tudo na minha vida.

Ao meu orientador Eurípedes do Amaral Vargas Júnior pela orientação, atenção e amizade.

Ao meu co-orientador José Tavares Araruna Júnior pela colaboração e orientação nos trabalhos de campo.

À pesquisadora Patrícia Österreicher Cunha pela ajuda e amizade constante.

Ao Professor Franklin Antunes por sempre compartilhar sua experiência com tanto carinho e auxiliar nos momentos decisivos.

Aos queridos amigos Patrício e Káthia pelo apoio e assistência nos ensaios de campo.

Ao Jayme de Paula Filho pela colaboração e contribuição com sua experiência.

Ao CNPq pelo apoio financeiro e à PUC-Rio pela oportunidade de trilhar os caminhos da pesquisa.

Aos funcionários do Labortório de Geotecnia Ambiental Amauri e Josué pela amizade e assistência. 
Aos amigos que conquistei nesta jornada na PUC-Rio pela ajuda e companheirismo.

À Profa. Maria Geralda de Carvalho da UFRRJ pela amizade, carinho, ajuda e compreensão em toda minha graduação e pós-graduação.

Aos Profs. da UFRRJ Maria Hilde de Barros Góes e Décio Tubbs Filho pela amizade e trocas acadêmicas.

Aos meus amigos da UFRRJ que sempre me apoiaram e nunca me abandonaram.

À todos os professores da UFRRJ que de alguma forma contribuíram para o andamento da pesquisa.

À pesquisadora Gisele Ramalho pela colaboração nos ensaios de campo.

À todos que de alguma forma fizeram parte deste trabalho.

À minha mãe que sempre esteve ao meu lado (literalmente) em todos os momentos e a quem devo minha vida.

Ao meu marido por toda a dedicação, carinho e amor, pois sem ele não seria possível boa parte do andamento da pesquisa.

À toda minha família que me apoiou todo o tempo. 


\section{Resumo}

Vicente, Jenesca Florêncio; Vargas Jr., Eurípedes do Amaral. Caracterização Hidrogeológica de uma Área Experimental no Campus da Universidade Federal Rural do Rio de Janeiro. Rio de Janeiro, 2008. 144p. Dissertação de Mestrado - Departamento de Engenharia Civil, Pontifícia Universidade Católica do Rio de Janeiro.

A contaminação da águas subterrâneas por substâncias orgânicas perigosas tem sido um assunto muito discutido atualmente devido a potencial escassez de água potável para utilização humana. Por esta razão pesquisas têm sido desenvolvidas para solução desse problema. Uma ferramenta usada é a utilização de áreas experimentais para o estudo do comportamento de contaminantes, do tipo derivados do petróleo, nas regiões saturadas e não saturadas do solo. Para a implantação de uma área experimental é necessária a compreensão dos parâmetros hidrogeológicos, físico-químicos e geoquímicos, a fim de desenvolver um monitoramento satisfatório do comportamento do futuro contaminante. Neste trabalho foram abordados estes parâmetros importantes para a implantação da área experimental no Campus da UFRRJ os quais foram comparados com os parâmetros das áreas experimentais de Borden (Ontário, Canadá), Cape Cod (Massachusetts, Estados Unidos) e Ressacada (Santa Catarina, Brasil). Os resultados da caracterização hidrogeológica demonstraram que os parâmetros físicos são semelhantes ao da área experimental de Borden e os parâmetros hidroquímicos são semelhantes ao da área experimental de Cape Cod. Assim, a área experimental da UFRRJ pode ser considerada viável para o estabelecimento de ensaios com substâncias derivadas do petróleo.

\section{Palavras-chave}

Hidrogeologia; Geoquímica; Área experimental. 


\section{ABSTRACT}

Vicente, Jenesca Florencio; Vargas Jr., Eurípedes do Amaral (Advisor). Hydrogeological Characterization of an Experimental Station at the Campus of Universidade Federal Rural do Rio de Janeiro. Rio de Janeiro, 2008. 144p. MSc. Dissertation - Departamento de Engenharia Civil, Pontifícia Universidade Católica do Rio de Janeiro.

The contamination of the underground waters for dangerous organic substances has been a subject very discussed now due to potential shortage of drinking water for human use. For this reason researches they have been developed for solution of that problem. An used tool is the use of experimental areas for the study of the behavior of pollutants, of the type derived of the petroleum, in the saturated areas and no saturated of the soil. To implant an experimental area it is necessary the understanding of the hydrogeological, physiochemical and geochemical parameter in order to develop a satisfactory monitoring of the behavior of the polluting future. In this work these important parameters were approached for the implantation of the experimental area in the Campus of UFRRJ which were compared with the parameters of the experimental sites of Borden (Ontario, Canada), Castrate Cod (Massachusetts, United States) and Ressacada (Santa Catarina, Brazil). The results of the hydrogeological characterization demonstrated that the physical parameters are similar to it of the experimental area of Borden and the hydrochemical parameters are similar to it of the experimental area of it Cape Cod. Thus the experimental site of UFRRJ can be considered viable for the establishment of rehearsals with derived substances of the petroleum

\section{Keywords}

Hydrogeology; Geochemistry; Experimental site. 


\section{Sumário}

1 INTRODUÇÃO 15

1.1. Objetivo 15

1.2. Composição da dissertação 16

2 CARACTERIZAÇÃO DO MEIO FÍSICO

2.1. Localização e Acesso 17

2.2. Geotectônica Regional 18

2.3. Geologia Local 19

2.4. Geomorfologia Local 21

2.5. Temperatura 22

2.6. Precipitação 24

2.7. Clima 25

2.8. Balando Hídrico 25

2.9. Hidrografia 27

2.10. Solos 27

2.11. Vegetação 30

3 REVISÃO BIBLIOGRÁFICA 31

4 METODOLOGIA $\quad 37$

4.1. Determinação da Área de Estudo

4.2. Trabalhos de Campo 40

4.2.1. Sondagens a trado mecânico 41

4.2.2. Levantamento topográfico 42

4.2.3. Instalação de poços de monitoramento 43

4.2.4. Mapa de fluxo da água subterrânea e gradiente hidráulico 44

4.2.5. Parâmetros físico-químicos 45

4.2.6. Permeabilidade "in situ" 47

4.2.7. Levantamento geofísico $\quad 54$

4.3. Ensaios de Laboratório $\quad 55$

4.3.1. Caracterização geotécnica $\quad 57$

$\begin{array}{ll}\text { 4.3.2. Permeabilidade indireta } & 57\end{array}$ 
4.3.3. Porosidade $\quad 58$

4.3.4. Análise geoquímica de amostras de sedimento e amostra de água 58

4.3.5. Difração de raio $X \quad 62$

4.4. Estudos Comparativos 63

5 RESULTADOS E DISCUSSÃO 65

5.1. Ensaios e Trabalhos de Campo 65

5.1.1. Levantamento topográfico 65

5.1.2. Mapa de fluxo da água subterrânea e gradiente hidráulico 67

5.1.3. Parâmetros físico-químicos 73

$\begin{array}{ll}\text { 5.1.4. Permeabilidade } & 79\end{array}$

5.1.5. Levantamento geofísico 79

5.2. Ensaios de Laboratório $\quad 80$

5.2.1. Caracterização geotécnica $\quad 80$

5.2.2. Porosidade 84

5.2.3. Análise geoquímica de amostras de sedimento e água 84

5.2.4. Difração de raio- $X \quad 88$

5.3. Velocidade da água subterrânea $\quad 89$

5.4. Análise comparativa entre as áreas experimentais 89

6 CONCLUSÃO E SUGESTÕES $\quad 94$

6.1. Conclusões 94

6.2. Sugestões 95

7 BIBLIOGRAFIA 96

8 ANEXOS 102 


\section{Lista de figuras}

Figura 1 - Mapa de localização da área de estudo (Adaptado de: Mapa Rodoviário do Estado do Rio de Janeiro, DNIT - 2002; Mapa do Rio de Janeiro, CIDE - 2001).

Figura 2 - Localização detalhada da área de estudo ao lado do Distrito Areeiro de Itaguaí-Seropédica. Os pontos em cor azul indicam os areais em exploração. (Detalhe da Folha do IBGE - SF.23-Z-AVI-4 e SF. 23-Z-C-III-2).

Figura 3 - Modelo deposicional da área de estudo (Adaptado de Góes, 1994).

Figura 4 - Mapa Geomorfológico do Estado do Rio de Janeiro.

Figura 5 - Média mensal de temperatura na área de estudo no período de 1973 a 2000.

Figura 6 - Média da temperatura no período de julho de 2007 a julho de 2008.

Figura 7- Média de precipitação mensal no período de 1973 a 2000.

Figura 8 - Precipitação mensal no período de julho de 2007 a julho de 2008.

Figura 9 - Balanço hídrico da região de Seropédica.

Figura 10 - Regime médio de evapotranspiração e precipitação de Seropédica.

Figura 11 - Mapa do Sistema Hidrográfico da Baia de Sepetiba (SEMA, 1996).

Figura 12 - Mapa do Levantamento Detalhado de Solos da UFRRJ.

Figura 13 - Relação entre o Rio Guandu e as Águas Subterrâneas (Tubbs, 2005).

Figura 14 - Mapa Potenciométrico Região da Piranema, Tubbs (2005), Modificado a partir da Eletrobolt, (2003).

Figura 15 - Mapa de localização das sondagens preliminares. 38

Figura 16 - Diagrama da estratigrafia local. 39

Figura 17 - Bloco diagrama da litologia local. $\quad 40$

Figura 18 - Sondagem na UFRRJ 41

Figura 19 - Perfuratriz executando a sondagem SP-04 na UFRRJ. 42

Figura 20 - Levantamento topográfico local. 43 
Figura 21 - Marco IBGE.

Figura 22 - Exemplo de um dos poços de monitoramento sendo instalados.

Figura 23 - Monitoramento do nível d'água.

Figura 24 - Troll 9.500 monitorando os parâmetros físico-químicos.

Figura 25 - Tabela de oxi-redução para vários receptores de elétrons (Stumm e Morgan, 1981).

Figura 26 - Esquema do slug test. (Ramesh, 1991)

Figura 27 - Parâmetros geométricos para o método de Hvorslev 1951 (Oliva et al, 2005).

Figura 28 - Parâmetros geométricos para o método de Bouwer and Rice 1976 (Oliva et al, 2005).

Figura 29 - Dimensionamento dos parâmetros A, B e C plotados em função de $L_{e} / R$. Estes parâmetros são usados na determinação de $\ln \left(R_{e} / R\right)$ nas equações acima descritas (7) e (8) Fetter (2001).

Figura 30 - Slug test no poço de monitoramento FJ-02.

Figura 31 - Datalogger no slug test.

Figura 32 - Mapa topográfico com a localização do perfil eletroresistividade.

55

Figura 33 - Coleta de amostra argilosa PUC-01.

56

Figura 34 - Coleta de amostra arenosa PUC-02.

56

Figura 35 - Topografia da área experimental.

Figura 36 - Localização em imagem de satélite dos poços de monitoramento.

Figura 37 - Mapa de fluxo da água subterrânea obtida através dos valores de carga hidráulica total $(\mathrm{m})$ na área de estudo em 18/02/2008.

Figura 38 - Mapa de fluxo da água subterrânea obtida através dos valores de carga hidráulica total $(\mathrm{m})$ na área de estudo em 05/06/2008.

Figura 39 - Mapa de fluxo da água subterrânea obtida através dos valores de carga hidráulica total $(\mathrm{m})$ na área de estudo em 10/07/2008.

Figura 40 - Mapa de fluxo da água subterrânea obtido através dos valores de carga hidráulica total $(\mathrm{m})$ na área de estudo em 01/08/2008. 
Figura 41 - Mapa de isolinhas com valores obtidos de $\mathrm{pH}$.

Figura 42 - Mapa de isolinhas com valores obtidos de temperatura em ${ }^{\circ} \mathrm{C}$.

Figura 43 - Mapa de isolinhas com valores obtidos de condutividade em $\mathrm{mS} / \mathrm{cm}$.

Figura 44 - Mapa de isolinhas com valores obtidos de potencial de oxiredução em $\mathrm{mV}$.

Figura 45 - Mapa de isolinhas com valores obtidos de oxigênio dissolvido em $\mathrm{mg} / \mathrm{L}$.

Figura 46 - Diagrama com valores interpolados de eletroresistividade.

80

Figura 47 - Curva granulométrica PUC-01.

82

Figura 48 - Curva granulométrica PUC-02.

83

Figura 49 - Diagrama de Piper da amostra FJ-03.

87

Figura 50 - Diagrama de Stiff da amostra FJ-03.

87

Figura 51 - Gráfico gerado pela difração de raio-x da amostra argilosa. $\quad 88$

Figura 52 - Gráfico gerado pela difração de raio-x da amostra arenosa.

88 


\section{Lista de tabelas}

Tabela 1 - Localização e níveis d'água dos poços de monitoramento.

Tabela 2 - Detalhes sobre as sondagens para fins de retirada de amostra deformada. $\quad 56$

Tabela 3 - Valores do coeficiente C para o método de Hazen. 58

Tabela 4 - Parâmetros geoquímicos analisados. $\quad 59$

Tabela 5 - Padrão de referência para contaminação de água e solo CETESB 2005 (adaptação). $\quad 59$

Tabela 6 - Lista Holandesa 1994 (adaptação). $\quad 61$

Tabela 7 - Resumo dos diversos padrões de potabilidade nacionais e internacionais (adaptado CETESB, 1990, in Feitosa et al, 2000). 62

Tabela 8 - Distâncias interplanares basais mais comuns 63

Tabela 9 - Pontos cotados na área de estudo. 66

Tabela 10 - Níveis d'água da área de estudo. 68

Tabela 11 - Carga hidráulica da área de estudo. 68

Tabela 12 - Gradiente hidráulico e direção de fluxo referentes à estação seca e chuvosa.

Tabela 13 - Parâmetros físico-químicos. $\quad 74$

Tabela 14 - Média da condutividade hidráulica da área pesquisada. $\quad 79$

Tabela 15 - Resumo da caracterização geotécnica. $\quad 81$

Tabela 16 - Média da porosidade local. $\quad 84$

Tabela 17 - Referência do laboratório. $\quad 84$

Tabela 18 - Resultados dos parâmetros geoquímicos das amostras dos sedimentos. 85

Tabela 19 - Resultados dos parâmetros geoquímicos das amostras de água. $\quad 86$

Tabela 20 - Resumo dos parâmetros hidrogeoquímicos de diversas áreas experimentais. 